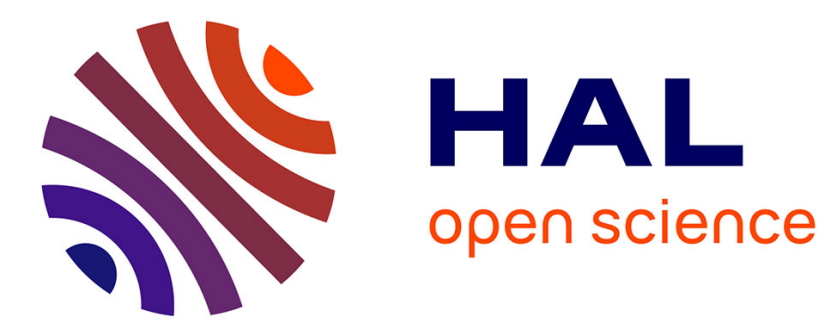

\title{
A fast, stepwise procedure to assess time-temperature equivalence for hydrothermal ageing of zirconia-based materials
}

Laurent Gremillard, Chong Wei, Jérome Chevalier, Karen Hans, Thomas

Oberbach

\section{To cite this version:}

Laurent Gremillard, Chong Wei, Jérome Chevalier, Karen Hans, Thomas Oberbach. A fast, stepwise procedure to assess time-temperature equivalence for hydrothermal ageing of zirconia-based materials. Journal of the European Ceramic Society, 2018, 38 (1), pp.181-186. 10.1016/j.jeurceramsoc.2017.08.018 . hal-01677777

\section{HAL Id: hal-01677777 \\ https://hal.science/hal-01677777}

Submitted on 8 Oct 2018

HAL is a multi-disciplinary open access archive for the deposit and dissemination of scientific research documents, whether they are published or not. The documents may come from teaching and research institutions in France or abroad, or from public or private research centers.
L'archive ouverte pluridisciplinaire HAL, est destinée au dépôt et à la diffusion de documents scientifiques de niveau recherche, publiés ou non, émanant des établissements d'enseignement et de recherche français ou étrangers, des laboratoires publics ou privés. 


\title{
A fast, stepwise procedure to assess time-temperature equivalence for hydrothermal ageing of zirconia-based materials
}

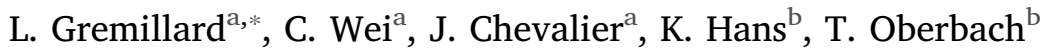

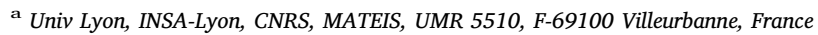 \\ ${ }^{\mathrm{b}}$ Mathys Orthopaedie GmbH, An den Trillers Bueschen 2, DE-07646 Moersdorf, Germany
}

\begin{abstract}
Hydrothermal ageing is one lifetime-limiting phenomenon of zirconia-based ceramics and composites for many applications, from biomedical implants to ferrules and watches. Predicting hydrothermal ageing at use-temperature implies a set of accelerated ageing experiments conducted under water vapour at several, high temperatures (usually between $100{ }^{\circ} \mathrm{C}$ and $140{ }^{\circ} \mathrm{C}$ ). From these data, the activation energy of ageing can be determined, and thus ageing can be predicted at any temperature. However, obtaining precise extrapolations with this procedure requires the use of lower temperatures $\left(70\right.$ or $80{ }^{\circ} \mathrm{C}$ ), leading to a rather long procedure (up to a few thousand hours), and should involve at least one specimen for each test temperature. This article presents a new procedure that allows the determination of all ageing parameters and the estimation of kinetics at usetemperatures with the use of a single specimen within a shorter time, accurate enough for fast screening of new materials.
\end{abstract}

\section{Introduction}

Zirconia ceramics can exist in three crystallographic phases at atmospheric pressure: cubic, tetragonal and monoclinic. The phase transition temperatures depend on many parameters, among which one of the most important is the nature and amount of stabilising oxides present in the ceramics. 3Y-TZP (tetragonal zirconia polycrystal stabilized with $3 \mathrm{~mol} \% \mathrm{Y}_{2} \mathrm{O}_{3}$ ) is the most used monolithic zirconia ceramic for biomedical applications, thanks to a combination of interesting properties: high toughness and strength (up to $6 \mathrm{MPa} \mathrm{m}^{1 / 2}$ and $1200 \mathrm{MPa}$ respectively), perfect biocompatibility, white colour and translucency. These good mechanical properties mainly come from Phase Transformation Toughening (PTT) that involves the tetragonalto-monoclinic $(\mathrm{t}-\mathrm{m})$ phase transformation around the tip of propagating cracks, the resulting volume increase acting to close the cracks and slow them, reinforcing the material [1]. However, the same t-m transformation can occur on surfaces in contact with water, and lead to roughening and microcracking [2]. This degradation phenomenon is called hydrothermal ageing (or Low Temperature Degradation) and is responsible for the decline of 3Y-TZP components in orthopaedics in the $2000 \mathrm{~s}$. To prevent it, several strategies exist. In particular aluminatoughened zirconia (ATZ) presents similar mechanical properties, while being less sensitive to ageing [3]. ZTA (standing for zirconia-toughened alumina) is also highly developed because of a higher resistance to ageing [4].

Ageing may occur at any temperature where tetragonal phase is metastable (for $3 \mathrm{Y}$-TZP, anywhere below $\sim 500{ }^{\circ} \mathrm{C}$ ). Over a certain temperature range (for 3Y-TZP between room temperature and more than $150^{\circ} \mathrm{C}$ ) it is a thermally activated phenomenon, thus faster at high temperature and slower at low temperature. To assess ageing at room (or body) temperature, it is thus convenient to extrapolate it from experiments made at higher temperature (typically in water and in autoclave, between 80 and $150{ }^{\circ} \mathrm{C}$ ). The typical procedure thus consists in measuring the evolution of monoclinic fraction with time of the surface of samples exposed to water (or steam) at different temperature, one sample being exposed to only one temperature until saturation of the monoclinic fraction. Then, from the ageing kinetics measured at (at least) two temperatures, an extrapolation to the temperature of interest can be conducted.

Any procedure to extrapolate ageing kinetics at low temperature is based on the fact that hydrothermal ageing is cumulative, and on two hypotheses:

1. Hydrothermal ageing is thermally activated in the temperature range used for the tests, thus the kinetics follow the same laws at $37^{\circ} \mathrm{C}$ as at higher temperatures.

2. The ageing exponent, $n$, is constant $v s$ temperature.

\footnotetext{
* Corresponding author.

E-mail address: laurent.gremillard@insa-lyon.fr (L. Gremillard).
} 
If these hypotheses are satisfied, the hydrothermal ageing kinetic can be expressed as the evolution of the monoclinic volume fraction $(V)$ $v s$ time by:

$$
\begin{gathered}
V(t, T)=1-\exp \left[-(b(T) \cdot t)^{n}\right] \\
\text { with } \mathrm{b}(t)=b_{0} \exp \left(\frac{-Q}{R T}\right)
\end{gathered}
$$

Thus the knowledge of the three ageing parameters $b_{0}, n$ and $Q$ allows the calculation of $V(t, T)$ for any ageing time and temperature.

The usual method [5] requires the determination of $V(t, T)$ at different temperatures, and determines analytically $\mathrm{b}_{0}, \mathrm{n}$ and $\mathrm{Q}$. Indeed, on can write Eq. (1) as:

$$
\begin{aligned}
\ln (1-V(t, T)) & =-(b(T) \cdot t)^{n} \operatorname{or} \ln \left(\ln \left(\frac{1}{1-V(t, T)}\right)\right) \\
& =n \ln (b(T))+n \ln (t)
\end{aligned}
$$

Thus, after Eq. (2), for each temperature, plotting $\ln \left(\ln \left(\frac{1}{1-V(t, T)}\right)\right)$ $v s \ln (t)$ gives a straight line of slope $n$. Then a common value of $n$ is chosen for all temperatures (usually the average of the values obtained at each temperature), and for each temperature a value of $b(T)$ is determined after the intercept of $\ln \left(\ln \left(\frac{1}{1-V(t, T)}\right)\right) v s \ln (t)$ (this intercept is: $n \cdot \mathrm{b}(T)$ ). Then plotting $\ln (\mathrm{b}(T)) v s 1 / T$ gives again a straight line of intercept $\ln \left(\mathrm{b}_{0}\right)$ and of slope $-\mathrm{Q} / \mathrm{R}$. This is a well-established method that gives correct results, but suffers from a few limitations that make it not always easy to use. In particular, it was shown [6] that $n$ may vary during a same kinetic. Thus the determination of $n$ and $b$ may depend on the person who makes the calculations.

Another, numerical, method starts from the same data $(V(t, T)$ at different temperatures), but minimizes the global error function $\varepsilon$ between the measured values and the ones predicted by Eq. (1) by optimizing the parameters $\mathrm{b}_{0}, \mathrm{n}$ and $\mathrm{Q}$.

$\varepsilon=\sum_{i} \frac{\sum_{j=1}^{N_{i}}\left(1-\exp \left[-\left(b_{0} \exp \left(-\frac{Q}{R T_{i}}\right) \cdot t_{j}\right)^{n}\right]-f_{i j}\right)^{2}}{N_{i}}$

Eq. (3) presents such an error function, in which each kinetic is given the same weight whatever the number of time points. In Eq. (3), $i$ relates to the number of temperatures tested and $j$ to the number of time points for each temperature (for 1 temperature $T_{i}, N_{i}$ time points are measured); $f_{i j}$ are the measured monoclinic fraction at temperature $T_{i}$ and time $t_{j}$. Many other error functions can be used, the other most frequent one being the one in which each experimental point is given the same weight. Optimization of $\mathrm{b}_{0}, \mathrm{n}$ and $\mathrm{Q}$ can be conducted numerically using a solver. This method presents the advantage to optimize all three parameters at once, and is less sensitive to measurement uncertainties. On the other hand, it must be considered with care since it will not directly reveal potential deviations from Eq. (1), contrary to the analytical method.

We propose here a new, stepwise method to extrapolate ageing kinetics to room temperature. It is based on ageing measurements at different temperature on a single sample, and can largely reduce the time necessary for correct extrapolations. In its principle it is similar to Locati procedure for the determination of mechanical fatigue limit [7], insofar as it calls on different levels of stress applied on a single sample (the "level of stress" being here a temperature) and on a "theoretical shape" of the physical quantity to characterize (fatigue limit follows a Wohler curve for Locati procedure, and here monoclinic content follows a Mehl Avrami Johnson law (Eq. (1)) for hydrothermal ageing). There are of course some differences between the method we propose here and Locati procedure. The main difference is that fatigue tests only rely on one single measurement: the number of cycles to fracture; they don't allow the evaluation of the damage parameter during the test. On the contrary, our procedure allows, and necessitates, the evaluation of the monoclinic fraction at every step of the test.
Table 1

\begin{tabular}{|c|c|c|c|c|c|}
\hline \multicolumn{2}{|c|}{ Schedule 1: SW1 } & \multicolumn{2}{|c|}{ Schedule 2: SW2A, SW2S } & \multicolumn{2}{|c|}{ Usual Schedule: UA, US } \\
\hline $\mathrm{T}_{\mathrm{i}}\left({ }^{\circ} \mathrm{C}\right)$ & $\Delta \mathrm{t}_{\mathrm{i}}(\mathrm{h})$ & $\mathrm{T}_{\mathrm{i}}\left({ }^{\circ} \mathrm{C}\right)$ & $\Delta \mathrm{t}_{\mathrm{i}}(\mathrm{h})$ & $\mathrm{T}\left({ }^{\circ} \mathrm{C}\right)$ & Total time (h) \\
\hline & 0 & & 0 & & 0 \\
\hline 141 & 4 & 141 & $4+2$ & 134 & 150 \\
\hline 134 & $3+4$ & 134 & $3+4$ & 111 & 650 \\
\hline 121 & 15 & 111 & $15+20$ & 90 & 3200 \\
\hline 111 & 40 & 75 & $200+300$ & & \\
\hline 100 & 120 & 90 & 100 & & \\
\hline 85 & 400 & 85 & 200 & & \\
\hline \multirow[t]{3}{*}{75} & 1000 & 100 & $50+100$ & & \\
\hline & & 121 & $40+40$ & & \\
\hline & & 134 & $10+10$ & & \\
\hline TOTAL & 1586 & & 1098 & & 4000 \\
\hline
\end{tabular}

Ageing kinetics schedules for the stepwise (SW) extrapolation procedure; Schedule SW1 and schedule SW2: all samples undergo the whole schedule; Usual schedule: three samples for each temperature.

\section{Materials and methods}

\subsection{Materials}

Experiments were conducted on commercially available aluminatoughened zirconia balls (ceramys ${ }^{\circledR}$, Mathys Orthopaedie, Moersdorf, Germany).

\subsection{Ageing procedure}

To assess the ageing procedure proposed here, hydrothermal ageing was conducted in autoclave (Wolf Sanoclav, Germany), in water vapour at different temperatures between 70 and $141{ }^{\circ} \mathrm{C}$, according to the schedules shown in Table 1 . Schedules 1 and 2 are used to apply the stepwise procedure (thus each sample is submitted to the whole schedule), whereas the Usual schedule refers to one single temperature per sample until saturation of the monoclinic fraction.

The monoclinic fractions were determined using X-Ray Diffraction (D8-Advance, Bruker, Germany) at every time point of the same schedule. XRD diagrams were acquired between 26 and $33 \mathrm{deg}$. 20, exposing the $(-111)$ and (111) monoclinic peaks, and (101) tetragonal peak. The volume monoclinic fraction $\left(f_{\mathrm{m}}\right)$ was deduced from these peaks intensities using Garvie and Nicholson's equation [8] modified by Toraya [9]:

$f_{m}=\frac{1.311 X_{m}}{1+0.311 X_{m}}$, with $X_{m}=\frac{I_{111}^{m}+I_{111}^{m}}{I_{111}^{m}+I_{111}^{m}+I_{101}^{t}}$

All ageing schedules were performed on 3 samples. All measurements of the monoclinic fraction were performed on two locations (pole and equator) of each sample.

\section{Theory/calculation}

\subsection{Extrapolation procedures}

The usual extrapolation procedures are described in the introduction. Here they are referred to as UA (usual schedule, analytical determination of the ageing parameters using Eq. (2)) and US (usual schedule, determination of the ageing parameters by global error minimisation using Eq. (3)).

The stepwise procedure presented here does not rely anymore on complete kinetics measured at different, constant temperatures. Instead, a single piece of zirconia-based material is submitted successively to different ageing temperatures. The single ageing kinetics obtained this way allows the determination of all three ageing parameters.

The method is based on a set of three equations obtained from Eq. (1), and on preliminary approach used to describe ageing at two 
alternating temperatures [10]. It is developed below.

Let's assume a completely tetragonal material before hydrothermal ageing $\left(\mathrm{V}\left(0, \mathrm{~T}_{0}\right)=0\right.$ whatever $\left.\mathrm{T}_{0}\right)$. Then a first accelerated ageing in autoclave is conducted at temperature $\mathrm{T}_{1}$ during time $\Delta \mathrm{t}_{1}$. The resulting monoclinic fraction is $V_{1}$ and could be calculated by Eq. (1). Then the temperature is changed to $\mathrm{T}_{2}$ and the material is aged again for a duration $\Delta t_{2}$. The resulting monoclinic fraction is $\mathrm{V}_{2}$. One cannot represent the points $\left(\Delta \mathrm{t}_{1}, \mathrm{~V}_{1}\right)$ and $\left(\Delta \mathrm{t}_{1}+\Delta \mathrm{t}_{2}, \mathrm{~V}_{2}\right)$ on the same curve, since they were obtained at different temperatures. Instead, one can estimate the "virtual time" $t_{2}$ that would have been necessary to reach the monoclinic fraction $V_{1}$ while ageing at the temperature $\mathrm{T}_{2}$. This time is given by:

$t_{2}=\frac{\sqrt[n]{-\ln \left(1-V_{1}\right)}}{b_{2}}$, with $b_{2}=b_{0} \exp \left(\frac{-Q}{R T_{2}}\right)$

Then, $V_{2}$ could be calculated with Eq. (6):

$V_{2}=1-\exp \left[-\left(b_{2} \cdot\left(t_{2}+\Delta t_{2}\right)\right)^{n}\right]$

This leads to an iterative procedure, in which the state of the material after the $i^{\text {th }}$ iteration (ageing at $T_{i}$ during $\Delta t_{i}$ ) is described by the following set of equations:

$V_{i}=1-\exp \left[-\left(b_{i} \cdot\left(t_{i}+\Delta t_{i}\right)\right)^{n}\right]$

$t_{i}=\frac{\sqrt[n]{-\ln \left(1-V_{i-1}\right)}}{b_{i}}$

$b_{i}=b_{0} \exp \left(\frac{-Q}{R T_{i}}\right)$

Note that for a material that retains a non-zero monoclinic fraction after sintering $\left(\mathrm{V}_{0}\right)$ and whose monoclinic fraction saturates at a fraction $V_{M}$ the set of Eqs. (7a)-(7c) can be changed to the set of Eqs. (8a)-(8c):

$V_{i}=V_{0}+\left(V_{M}-V_{0}\right) \cdot\left\{1-\exp \left[-\left(b_{i} \cdot\left(t_{i}+\Delta t_{i}\right)\right)^{n}\right]\right\}$

$t_{i}=\frac{1}{b_{i}} \sqrt[n]{\ln \left(\frac{V_{M}-V_{0}}{V_{M}-V_{i-1}}\right)}$

and

$b_{i}=b_{0} \exp \left(\frac{-Q}{R T_{i}}\right)$

The result of an ageing experiment following this procedure is thus a list of $\left[\left(T_{i}, \Delta t_{i}, V_{i}\right), \mathrm{i}=1,2, \ldots\right]$ (list in which all $T_{i}$ are not necessarily different). From this list one can extract $n, Q$ and $b_{o}$ (and $V_{o}$ and $V_{M}$ if necessary) either analytically or using a numerical optimization procedure (simply put, a solver).
Indeed, if one uses twice the same temperature $\left(T_{2}=T_{1}\right)$ for the two first iterations $\left(t_{1}=0\right)$, it follows that $b_{2}=b_{1}$, and the situation can be described by:

$V_{1}=1-\exp \left[-\left(b_{1} \cdot\left(\Delta t_{1}\right)\right)^{n}\right]$ and

$V_{2}=1-\exp \left[-\left(b_{1} \cdot\left(\Delta t_{1}+\Delta t_{2}\right)\right)^{n}\right]$

Which leads to the knowledge of $n$ by:

$n=\frac{\ln \left(\ln \left(\frac{1}{1-V_{1}}\right)\right)-\ln \left(\ln \left(\frac{1}{1-V_{2}}\right)\right)}{\ln \left(\Delta t_{1}\right)-\ln \left(\Delta t_{1}+\Delta t_{2}\right)}$

Moreover, incorporating a time increment $\Delta t_{i}$ of 0 in Eq. (7a) leads to:

$V_{i}=V_{i-1}=1-\exp \left[-\left(b_{i} \cdot t_{i}\right)^{n}\right]$

Combined with Eq. (7a):

$\frac{1-V_{i-1}}{1-V_{i}}=\frac{\exp \left[-\left(b_{i} \cdot t_{i}\right)^{n}\right]}{\exp \left[-\left(b_{i} \cdot\left(t_{i}+\Delta t_{i}\right)\right)^{n}\right]}=\exp \left[\left(b_{i} \cdot\left(t_{i}+\Delta t_{i}\right)\right)^{n}-\left(b_{i} \cdot t_{i}\right)^{n}\right]$

or $\ln \left(\frac{1-V_{i-1}}{1-V_{i}}\right)=\left(b_{i} \cdot\left(t_{i}+\Delta t_{i}\right)\right)^{n}-\left(b_{i} \cdot t_{i}\right)^{n}$

If $\Delta t_{i}$ is small enough as compared to $t_{i}$, then $V_{i}$ is very close to $V_{i-1}$, then a first order limited development of the exponential, a classical equivalent of the logarithm and a combination with Eq. (7c) give:

$\frac{1}{\Delta t_{i}} \ln \left(\frac{1-V_{i-1}}{1-V_{i}}\right) \sim n b_{i} \sim n b_{0} \exp \left(\frac{-Q}{R T_{i}}\right)$

$\ln \left[\frac{1}{\Delta t_{i}} \ln \left(\frac{1-V_{i-1}}{1-V_{i}}\right)\right] \sim \ln \left(n b_{0}\right)-\frac{Q}{R T_{i}}$

Thus plotting $\ln \left[\frac{1}{\Delta t_{i}} \ln \left(\frac{1-V_{i-1}}{1-V_{i}}\right)\right]$ versus $\frac{1}{R T_{i}}$ between two close points (small $\Delta t_{i}$ as compared to $t_{i}$ ) gives a straight line of slope $-Q$ and intercept $\ln \left(n b_{0}\right)$, thus $b_{o}$ can be calculated thanks to the previous knowledge of $n$.

\section{Results}

Fig. 1 shows the determination of $\mathrm{n}, \mathrm{b} 0$ and $\mathrm{Q}$ using the classical, analytical approach (three complete kinetics measured at 90, 111 and $134^{\circ} \mathrm{C}$, analysed using Eq. (2)). It confirms that $\mathrm{n}$ is almost independent on the temperature. Here a value of 0.94 was chosen for $n$ (average of the three slopes reported on Fig. 1(a)). From these parameters (reported in Table 2 in the column ZTA-UA) one can calculate the ageing kinetics at the same temperatures and extrapolate at $37{ }^{\circ} \mathrm{C}$. The result is shown on Fig. 2(a). Using the same set of experimental points, one can
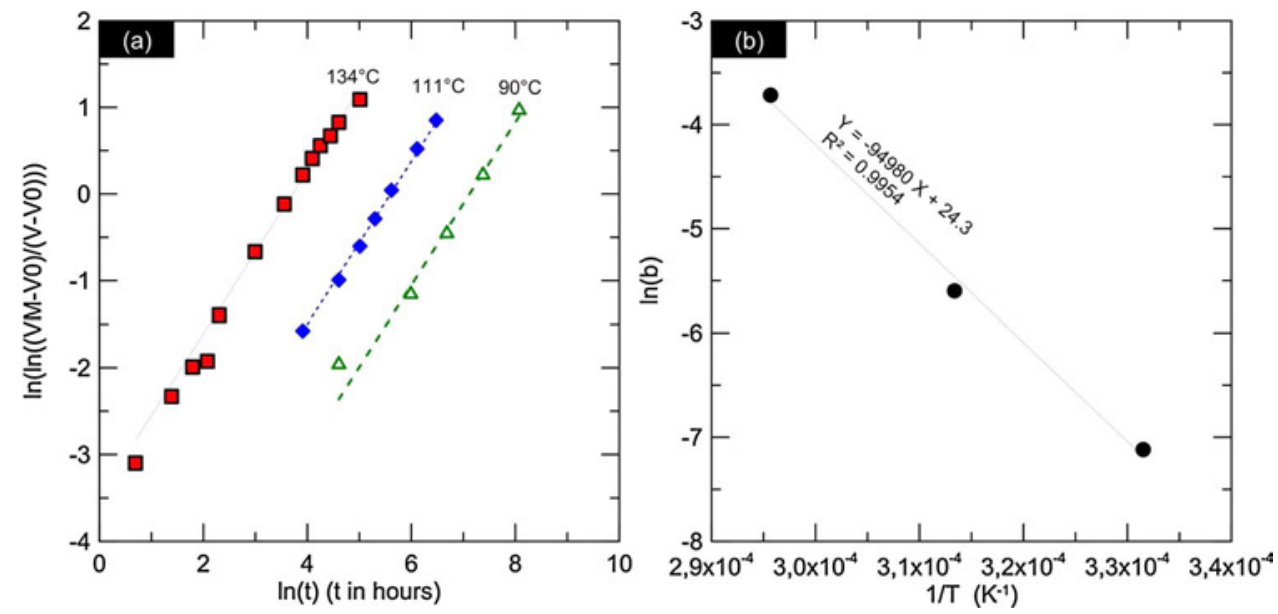

Fig. 1. Calculation of $n, b 0$ and $Q$ according to the analytical procedure. 
Table 2

Parameters for ageing of ATZ according to the different ageing procedures.

\begin{tabular}{|c|c|c|c|c|c|}
\hline & Analytical (UA) & Solver (US) & Stepwise Schedule 1 solver (SW1) & Stepwise Schedule 2 Analytical (SW2A) & Stepwise Schedule 2 solver (SW2S) \\
\hline $\mathrm{V}_{0}$ & 0.013 & 0.013 & 0.013 & 0.013 & 0.013 \\
\hline $\mathrm{V}_{\mathrm{M}}$ & 0.75 & 0.75 & 0.75 & 0.75 & 0.75 \\
\hline$b_{0}\left(h^{-1}\right)$ & $3.6 \cdot 10^{10}$ & $3.6 \cdot 10^{10}$ & $4.5 \cdot 10^{11}$ & $1.1 \cdot 10^{11}$ & $1.1 \cdot 10^{12}$ \\
\hline $\mathrm{Q}(\mathrm{kJ} / \mathrm{mol})$ & 95.0 & 95.3 & 102.8 & 100.2 & 105.7 \\
\hline b at $37^{\circ} \mathrm{C}$ & $3.5 \cdot 10^{-6}$ & $3.1 \cdot 10^{-6}$ & $2.1 \cdot 10^{-6}$ & $1.4 \cdot 10^{-6}$ & $1.7 \cdot 10^{-6}$ \\
\hline $\mathrm{n}$ & 0.94 & 0.98 & 0.95 & 0.84 & 0.96 \\
\hline Overall error & $5.3 \cdot 10^{-3}$ & $1.2 \cdot 10^{-2}$ & $1.2 \cdot 10^{-4}$ & $2.2 \cdot 10^{-1}$ & $2.8 \cdot 10^{-3}$ \\
\hline Error/point & $1.9 \cdot 10^{-4}$ & $4.4 \cdot 10^{-4}$ & $1.3 \cdot 10^{-5}$ & $1.4 \cdot 10^{-2}$ & $1.8 \cdot 10^{-4}$ \\
\hline time in autoclave (h) & 4000 & 4000 & 1586 & 1098 & 1098 \\
\hline $\mathrm{Nb}$ of XRD measurements & 28 & 28 & 9 & 17 & 17 \\
\hline
\end{tabular}

minimize the error function described in Eq. (3) to obtain directly another set of parameters (reported in Table 2 in the column ZTA-US). The kinetics calculated using this new set are reported in Fig. 2(b). In both cases, a good fit of all experimental data is obtained.

Fig. 3 shows the results obtained from the schedule 1 of the stepwise procedure (see SW1 on Table 1). The calculation of the ageing kinetics parameters was conducted using a solver, and minimizing the difference between the experimental values of the monoclinic fraction and the calculated ones. A very good agreement is reached. However, since only one point was used for each temperature, an analytical determination of the ageing parameters was not possible. The values of $n, b_{0}$ and $\mathrm{Q}$ found for the best fit are reported in Table 2 (column SW1).

Schedule 2 (see Table 1, SW2) was devised so that the measurements at lower temperatures occur during the fastest increase of monoclinic fraction with ageing time (above $30 \%$ monoclinic fraction). This decreases again the total ageing time by a factor of almost 1.5 as compared to schedule 1 . Moreover, an analytical determination of $n, b_{0}$ and $\mathrm{Q}$ was made possible by incorporating intermediate time points at several temperatures (see Table 1). The results are shown on Fig. 4 and were exploited using two procedures.

In the first one, $n$ was determined from the two first points at $141{ }^{\circ} \mathrm{C}$ according to Eq. (10). Knowing $n$, it was possible to plot $\ln \left[\frac{1}{\Delta t_{i}} \ln \left(\frac{1-V_{i-1}}{1-V_{i}}\right)\right]$ versus $\frac{1}{R T_{i}}$ at the different temperatures (Fig. 4(b)) to determine the activation energy $(100 \mathrm{~kJ} / \mathrm{mol})$ and $b_{0}$ according to Eq. (13b). However it can be seen that the agreement between measured and calculated monoclinic fractions is not very good. These results are reported in the column SW2A of Table 2.

Using the same dataset the second procedure called upon a numerical optimization procedure (solver) to minimize the global error by adjusting $\mathrm{b}_{0}, \mathrm{Q}$ and $\mathrm{n}\left(\mathrm{V}_{0}\right.$ and $\mathrm{V}_{\mathrm{Max}}$ being known from UA or US procedures). The resulting kinetics are displayed on Fig. 5, and show a much better agreement between calculations and experiment. Once

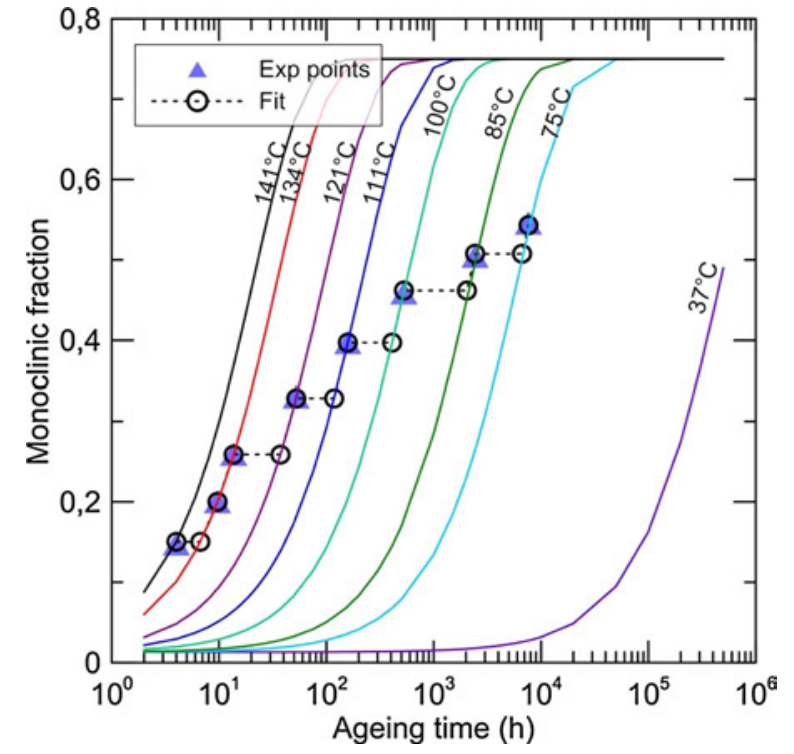

Fig. 3. Ageing kinetics of ATZ calculated after the SW1 procedure, using schedule 1 and a numerical optimization; experimental datapoints are represented by blue triangles; calculated datapoints are shown as open circles; calculated kinetics are shown as continuous lines. (For interpretation of the references to colour in this figure legend, the reader is referred to the web version of this article.)

again the ageing kinetics parameters are reported in Table 2 (column SW2S).

From the parameters reported on Table 2, it is possible to extrapolate all the measured kinetics at $134^{\circ} \mathrm{C}$ and at body temperature $\left(37^{\circ} \mathrm{C}\right.$ ) (Fig. 6). At $134^{\circ} \mathrm{C}$, all (but one) extrapolated kinetics agree reasonably well with the measured kinetics. Only SW2A set of
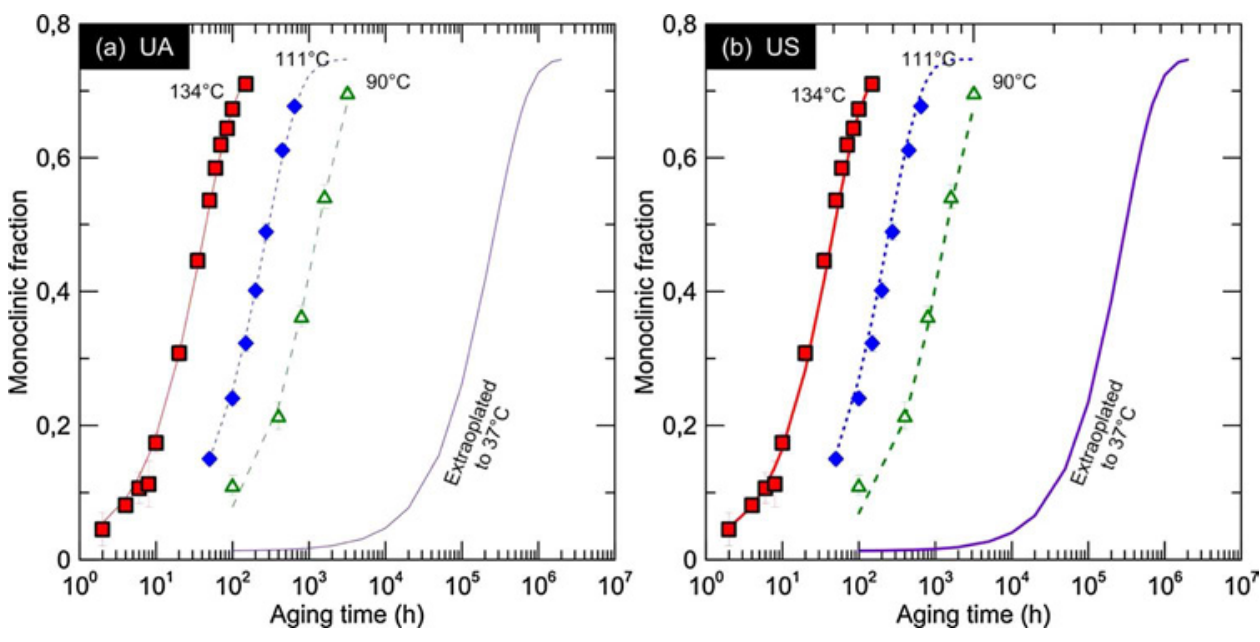

Fig. 2. Aging kinetics of ATZ using the classical procedure. (a): fit parameters derived from an analytical approach (UA); (b): fit parameters derived from a numerical global error minimization (US). 

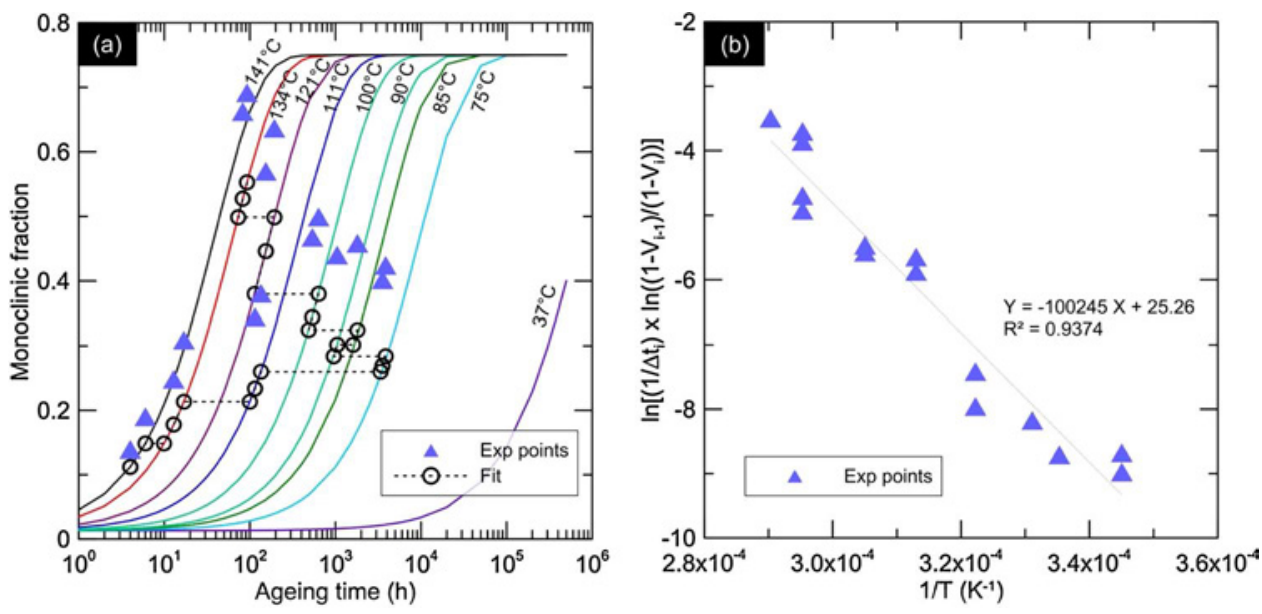

Fig. 4. Ageing kinetics calculated after the stepwise procedure (schedule 2 , analytical).

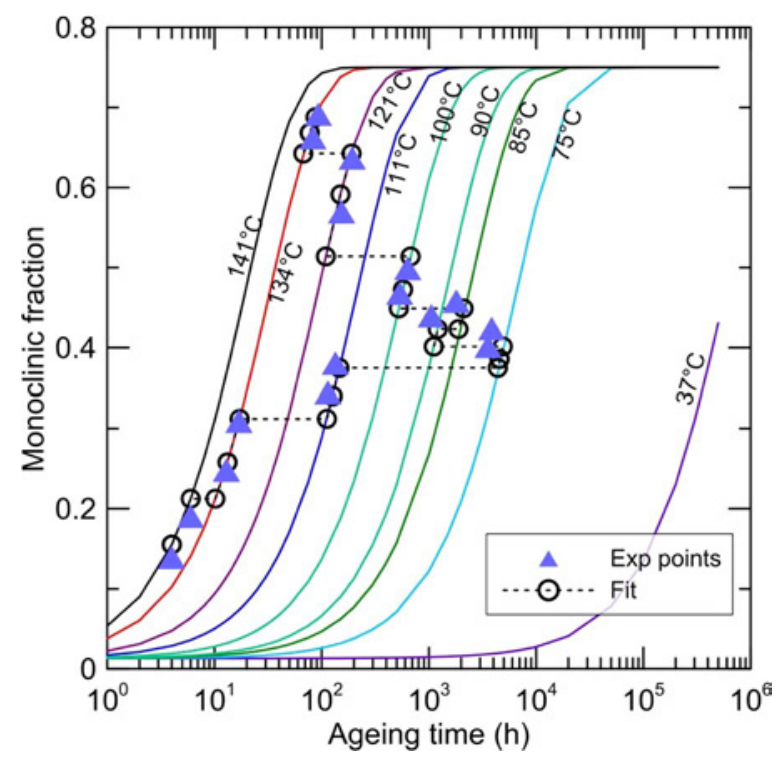

Fig. 5. Ageing kinetics calculated after the stepwise procedure, schedule 2, with a numerical optimization.

parameters results in an incorrect extrapolation that underestimate the ageing kinetics.

At $37{ }^{\circ} \mathrm{C}$ no experimental determination of the ageing kinetics of ATZ is possible in a reasonable timeframe. Taking as a reference the extrapolation realised using the classical, analytical procedure (UA), it can be seen that all other extrapolations lie below although they are in the same order of magnitude. For example, at $200000 \mathrm{~h}$ (23 years) the calculated monoclinic fractions lie between 0.23 (SW2A) and 0.39 (US). Conversely the times necessary to reach $40 \%$ monoclinic fraction lie between $200000 \mathrm{~h}$ (23 years, UA) and $500000 \mathrm{~h}$ (57 years, SW2A). All other extrapolations lie between UA and SW2A.

\section{Discussion}

The parameters shown in Table 2 reveal some interesting findings:

- First, the experimental values of $\mathrm{V}_{0}$ and $\mathrm{V}_{\mathrm{M}}$ (resp. 0.013 and 0.75, measured during a whole ageing kinetics at $134^{\circ} \mathrm{C}$ ) are adequate for all fitting procedure.

- Second, the values of $n$ are also very close: from 0.94 to 0.98 , with one exception (SW2A for which $n=0.84$, due to the fact that for SW2A $\mathrm{n}$ is determined from only 2 early time points, whereas for the other procedures all time points are taken into account).

- Third, there is more scattering in the values of the activation energy and of $b_{0}$. However, when using $b_{0}$ and $Q$ to calculate $b$ at $37{ }^{\circ} \mathrm{C}$, all values of $b$ are in the same range $\left(1.4 \cdot 10^{-6}\right.$ (SW2A) to $3.5 \cdot 10^{-6}$ (UA)). Since $b$ is closely related to the transformation speed (high $b$ means fast transformation), all kinetics at $37^{\circ} \mathrm{C}$ also lie in the same range.

In fact, since $n$ is the same for all extrapolation procedures (except SW2A), the parameter b (at $37^{\circ} \mathrm{C}$ ) directly controls the speed of ageing at $37^{\circ} \mathrm{C}$. This explains why the values of $\mathrm{b}\left(\right.$ at $37^{\circ} \mathrm{C}$ ) are ordered in the same way as the ageing kinetics extrapolated at the same temperature: SW2A $<$ SW2S $<$ SW1 $<$ US $<$ UA (where the sign " $<$ " indicates a

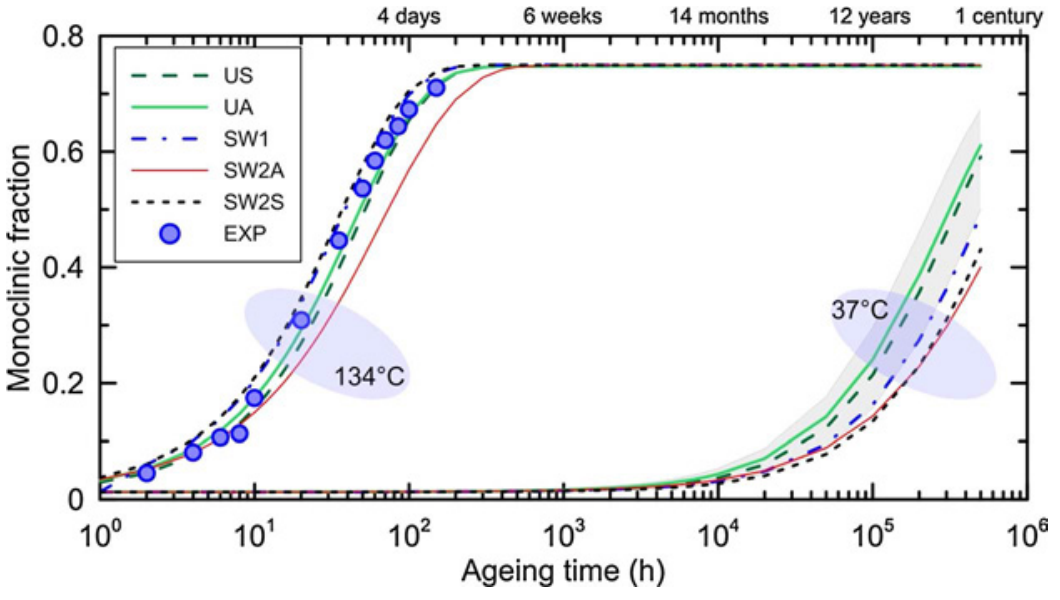

Fig. 6. Calculations of the monoclinic fraction vs time at $134{ }^{\circ} \mathrm{C}$ and at $37^{\circ} \mathrm{C}$ using the different ageing procedures. Experimental points are measurements taken at $134^{\circ} \mathrm{C}$ during the Usual Schedule. 
smaller value of $\mathrm{b}$ and a slower kinetic). On Fig. 6, the grey band indicates an interval of confidence calculated from the data of the classical procedure. Except for SW2A and SW2S, all extrapolation procedures lead to equivalent ageing kinetics at $37{ }^{\circ} \mathrm{C}$ (all kinetics fall inside the interval of confidence).

This leads us to wonder why the two SW2 procedures are outside this band. SW2A proves to be the least precise. It is probably related to the way $n$ is calculated (Eq. (10)), taking into account only the two first experimental points. Moreover, ensuring that $\Delta \mathrm{t}_{\mathrm{i}}$ is small enough as compared to $\mathrm{t}_{\mathrm{i}}$ means that $\mathrm{V}_{\mathrm{i}}$ and $\mathrm{V}_{\mathrm{i}-1}$ are similar. Thus small, unavoidable errors on the measurement of $V_{i}$ will cause large relative errors on $\mathrm{V}_{\mathrm{i}}-\mathrm{V}_{\mathrm{i}-1}$, thus a large imprecision on $\mathrm{Q}$ and $n \cdot \mathrm{b}_{0}$ obtained by Eq. (13b) if one tries this analytical approach. In conclusion the SW2A procedure should not be used alone; however it can prove useful to provide initial parameters for the global error minimization of SW2S.

The difference between SW2S and the other procedures (UA, US, SW1) may be attributed to the less important weight given in this procedure to the lowest temperatures: in SW2S (and SW2A) 15\% of the total increase of the monoclinic fraction during ageing can be attributed to temperatures equal to or lower than $100{ }^{\circ} \mathrm{C}$. In SW1, this figure rises to $27 \%$, and to $32 \%$ in UA and US (taking into account all kinetics at all temperatures). On the other hand, schedule 1 does not lead to saturation of the monoclinic fraction.

SW1 and SW2 procedures present several advantages over the classical ones:

1. They are faster: SW1 requires around $1600 \mathrm{~h}$ to test ageing at 7 different temperatures, covering here a $75-141{ }^{\circ} \mathrm{C}$ temperature range; SW2 requires less than $1100 \mathrm{~h}$ to cover the same temperature range. UA and US necessitate $4000 \mathrm{~h}$ to establish the full kinetics at 3 different temperatures $\left(90,111,134^{\circ} \mathrm{C}\right)$; this time would go up to $12000 \mathrm{~h}$ to measure whole kinetics at the same 7 temperatures. SW2 represents then a gain of time by a factor of 4-11.

2. They necessitate less XRD measurements ( 28 for UA and US, 9 for SW1, 16 for SW2).

3. They require much less samples: a single sample is enough for SW1 and SW2, whereas UA and US necessitate at least one sample per temperature (here at least 3 ).

It is rather difficult to decide what extrapolation procedure gives the most precise results. One might decide on choosing the worst case. But it is doubtful that the worst case will always be given by the UA procedure.

In our opinion, the UA procedure may prove to be the most accurate, provided it's conducted at both low (down to 80 or $70{ }^{\circ} \mathrm{C}$ ) and high (up to $150{ }^{\circ} \mathrm{C}$ ) temperatures, which is not the case here. On the other hand, this procedure will be so long that it cannot be used to assess numerous new materials. In the framework of zirconia-based materials development, schedule SW1 may be a good option to compare relatively quickly between several materials. Of course, the schedules presented here are not the only ones possible, and further developments could be implemented in the case of completely unknown materials (for example, start with a few hours at $134^{\circ} \mathrm{C}$, and change the ageing temperature after each $10 \%$ increase of the monoclinic fraction). In all cases, it is always advisable to start with the measurement of a whole kinetics at high temperature, thus gaining access to more precise initial values of $n, V_{0}$ and $V_{M a x}$, while $b_{0}$ and $Q$ will be known after a $S W$ schedule.
Finally, it is worthy to point out that although the measurements of monoclinic fraction after each ageing step are mandatory, X-ray diffraction is not the only method available. The stepwise procedure presented here should give similar results when using Raman spectroscopy $[11,12]$ or any other 'evolution indicator' to measure the monoclinic fractions.

\section{Conclusion}

This article presents a stepwise procedure to determine the parameters of hydrothermal ageing of zirconia-containing ceramics. This procedure relies on ageing at different temperatures applied on a same sample. It is shown to be faster than usual ones (relying on a single temperature per sample) and less costly (necessitating less time, only one sample and fewer measurement of the monoclinic fraction). The extrapolation to $37^{\circ} \mathrm{C}$ realised using both usual and stepwise procedures lie in the same order of magnitude. However they are not exactly alike. It is suggested that the stepwise procedure should be used for fast screening of new materials, while a more precise extrapolation may be provided by the usual procedure extended to lower temperatures.

\section{Acknowledgment}

C. Wei was supported by a grant from the Chinese Science Council.

\section{Appendix A. Supplementary data}

Supplementary data associated with this article can be found, in the online version, at http://dx.doi.org/10.1016/j.jeurceramsoc.2017.08. 018.

\section{References}

[1] J. Chevalier, L. Gremillard, A.V. Virkar, D.R. Clarke, The tetragonal-monoclinic transformation in Zirconia: lessons learned and future trends, J. Am. Ceram. Soc. 92 (2009) 1901-1920.

[2] J. Chevalier, L. Gremillard, S. Deville, Low-temperature degradation of Zirconia and implications for biomedical implants, Annu. Rev. Mater. Res. 37 (2007) 1-32.

[3] J. Schneider, S. Begand, R. Kriegel, C. Kaps, W. Glien, T. Oberbach, Low-temperature aging behavior of alumina-toughened zirconia, J. Am. Ceram. Soc. 91 (2008) 3613-3618.

[4] J. Chevalier, S. Grandjean, M. Kuntz, G. Pezzotti, On the kinetics and impact of tetragonal to monoclinic transformation in an alumina/zirconia composite for arthroplasty applications, Biomaterials 30 (2009) 5279-5282.

[5] J. Chevalier, B. Cales, J.M. Drouin, Low-temperature aging of Y-TZP ceramics, J. Am. Ceram. Soc. 82 (1999) 2150-2154.

[6] L. Gremillard, J. Chevalier, T. Epicier, S. Deville, G. Fantozzi, Modeling the aging kinetics of zirconia ceramics, J. Eur. Ceram. Soc. 24 (2004) 3483-3489.

[7] L. Locati, La Metall. Ital. 47 (1955) 301-308.

[8] R.C. Garvie, P.S. Nicholson, Phases analysis in zirconia systems, J. Am. Ceram. Soc. 55 (1972) 303-305.

[9] H. Toraya, M. Yoshimura, S. Somiya, Calibration curves for the quantitative analysis of the monoclinic-tetragonal $\mathrm{ZrO}_{2}$ system by X-ray diffraction, J. Am. Ceram. Soc. 67 (1984) C119-C121.

[10] L. Gremillard, L. Martin, L. Zych, E. Crosnier, J. Chevalier, A. Charbouillot, P. Sainsot, J. Espinouse, J.L. Aurelle, Combining ageing and wear to assess the durability of zirconia-based ceramic heads for total hip arthroplasty, Acta Biomater. 9 (2013) 7545-7555.

[11] D.R. Clarke, F. Adar, Measurement of the crystallographically transformed zone produced by fracture in ceramics containing tetragonal zirconia, J. Am. Ceram. Soc 65 (1982) 284-288.

[12] G. Pezzotti, K. Yamada, S. Sakakura, R.P. Pitto, Raman spectroscopic analysis of advanced ceramic composite for hip prosthesis, J. Am. Ceram. Soc. 91 (2008) 1199-1206. 